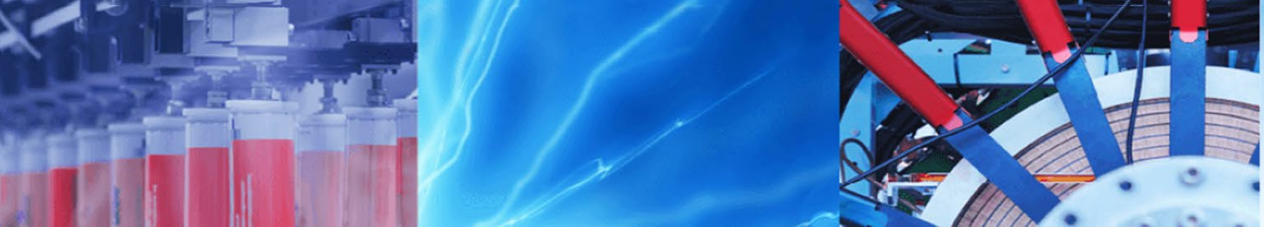

Research Article

\title{
Batch anaerobic co-digestion of food waste and sludge: a multi criteria decision modelling (MCDM) approach
}

\author{
Nupur Kesharwani ${ }^{1}$. Samir Bajpai ${ }^{1}$
}

Received: 30 January 2020 / Accepted: 27 July 2020 / Published online: 2 August 2020

(c) Springer Nature Switzerland AG 2020

\begin{abstract}
The present study investigates the application of Multi Criteria Decision Modelling (MCDM) on batch anaerobic codigestion of kitchen food waste (FW) and the fresh septic tank sludge (STS) for robust output. The batch experiment was carried out at a temperature of $37 \pm 2{ }^{\circ}$ C. Different ratio of FW and STS (FW: STS:100:0; 75:25; 60:40; 50:50; 25:75; 0:100) were adopted based on volatile solid (VS) basis as co digestion strategy for 90 days digestion period. Results revealed that experimentally, mono-digestion of FW showed maximum biogas yield ( $544 \pm 65 \mathrm{~mL} / \mathrm{g} \mathrm{VS}$ ) followed by blending ratio of 75:25 (FW: STS). However, mono-digestion of STS showed only $150 \pm 15 \mathrm{~mL} / \mathrm{g} \mathrm{VS}$ of biogas yield and also showed negative effect on co digestion with FW for every blending on VS basis as STS was high in minerals. MCDM revealed that the FW is the best possible alternative amongst the other blends with STS considering $\mathrm{pH}$, chemical oxygen demand, VS reduction, alkalinity, $\mathrm{C} / \mathrm{N}$ and biogas yield as output.
\end{abstract}

Keywords Food waste $\cdot$ Septic tank sludge $\cdot$ MCDM - Biogas · Principal component analysis

\section{Introduction}

Anaerobic digestion for organic wastes has been widely applied by researchers often coupled with energy recovery through biogas [1]. Minimization of carbon footprints is a major challenge for investigators and practitioners of waste and wastewater treatment [2]. Anaerobic processes may be helpful in minimizing waste as well as producing renewable energy and high value manure. On the other hand, aerobic processes may not helpful in reducing waste significantly and does not provide energy carrier.

Organic fraction present in municipal waste may be utilized for methane production in anaerobic condition [3]. Anaerobic digestion (AD) is a natural phenomenon governed by microbial consortia which converting organic waste into fuel (methane). The constituents of biogas divided into two major part as $\mathrm{CH}_{4}(\sim 65 \%)$ and $\mathrm{CO}_{2}(\sim 35 \%)$ along with few undesirable impurities [4]. It was reported that significant fraction of municipal waste is waste in the form of food (FW) [5] and around 1.3 billion tonnes of food remain unutilized and emerges as waste [6]. The recovery of nutrients and energy from food waste is an essential requirement for the sustainable development of mankind.

Conventionally, AD has been considered as sole technique for waste treatment and minimization. However, digesting multiple feedstock from different origin as codigestion technique may maximized the output of the process. It was also reported that digesting multiple waste into $A D$ reactor helps to alleviate the quality and quantity of biogas [7]. The enhancement of biogas yield from anaerobic digester requires co-substrates which establish

Electronic supplementary material The online version of this article (https://doi.org/10.1007/s42452-020-03265-1) contains supplementary material, which is available to authorized users.

Nupur Kesharwani, nkesharwani.phd2016.ce@nitrr.ac.in; Samir Bajpai, sb@nitrr.ac.in | 1 Department of Civil Engineering, National Institute of Technology, Raipur, Chhattisgarh, India. 
positive synergisms between the digestion medium and the co-substrates that compensate for the missing nutrients. For assessing the effect of anaerobic co-digestion, batch test at lab scale of the selected substrate may be performed [8]. Koch et al. [9] asserted that that kinetic study and changes related to anaerobic co digestion might be examined in batch tests.

Marañón et al. [10] obtained maximum methane yield of $603 \mathrm{LCH}_{4} / \mathrm{kg}$ VS feed with Organic Loading Rate of $1.2 \mathrm{~g}$ VS/L for the feedstock of cattle manure, food waste and sewage sludge in the proportion of 70:20:10 (total solid concentration around $4 \%$ ) at $36^{\circ} \mathrm{C}$. Mashad and Zhang [11] studied the effect of manure particles sizes on the biogas yield of screened dairy manure with food waste under mesophilic conditions $\left(35^{\circ} \mathrm{C}\right)$ in batch digesters for a period of 30 days. After 30 days, the methane yields obtained were $302 \mathrm{~L} / \mathrm{kg}$ VS for fine screened manure, 228 $\mathrm{L} / \mathrm{kg}$ VS for coarse screened manure and $241 \mathrm{~L} / \mathrm{kg}$ VS for the manure that was unscreened, establishing that higher surface area results in higher methane yield. On the other hand, septic tank sludge (STS) imparts nutrients and organic matter in abundance as it contains a major portion of human excreta [12]. The nutrients and organic matter will further increase if the septic tank sludge is added during treatment as supplemental feedstock with the FW, resulting in possible improvement in treatment efficiency.

Multi Criteria Decision Modelling (MCDM) may be helpful for selecting best input condition depending on the various output. In a reported study, MCDM helped to prioritize the temperature and solid concentration for solid state anaerobic digestion of pearl millet straw [13]. It was also concluded by previous researcher that experimental results of anaerobic digestion may be verified using the MCDM. However, there is scarcity of literature on application of MCDM on anaerobic co-digestion for robust output.

Thus, the objectives of present study were (a) to perform batch scale anaerobic co-digestion of FW and STS and (b) to apply MCDM on output of anaerobic co-digestion of FW and STS.

\section{Materials and methods}

\subsection{Collection of food waste and sludge}

The food waste (FW) and fresh septic tank sludge (STS) were mixed in different proportions to conduct the bio methane potential test. The STS was collected from the recently cleaned septic tank of the faculty quarters at NIT Raipur $\left(21.2497^{\circ} \mathrm{N}, 81.6050^{\circ} \mathrm{E}\right)$ after 5 days of operation. The FW was collected from the girls' hostel of NIT Raipur for 1 week and refrigerated to achieve uniformity in the mixture [14]. The FW comprised of cooked rice, chapattis, salad, cooked vegetables, pulses and miscellaneous. For characterisation, a portion of food waste was incubated at a temperature of $70^{\circ} \mathrm{C}$ for almost $8 \mathrm{~h}$ to preserve the chemical characteristics [14]. The septic tank sludge was also dried similarly. The dried food waste was grinded into smaller pieces. Dried and grinded food waste and septic tank sludge were analysed for heavy metals, $\mathrm{pH}$, and alkalinity and for ultimate analysis to find out the percentage composition of carbon, nitrogen, hydrogen and oxygen in order to find out the $\mathrm{C} / \mathrm{N}$ ratio. Proximate analysis was conducted on a portion of the grinded and the non-dried food waste and anaerobic sludge to find out the values of moisture content, total solids and Volatile solids. To measure $C O D$, the liquid was obtained by squeezing the grinded food waste through a dry and clean cotton cloth, which was used for COD analysis [15]. The COD determined here is soluble COD.

\subsection{Preparation of inoculum}

The inoculum was the fresh cow dung collected from a local dairy. For degassing, the inoculum was pre-incubated at the similar temperature as for the process temperature (i.e. $37^{\circ} \mathrm{C}$ ) for 30 days prior to conducting the experiments to deplete the residual biodegradable organic material present in it and to activate anaerobic methanogens [16]. The inoculum was mixed with sufficient quantity of distilled water to have a total solids concentration of $1.5-2 \mathrm{~g} / \mathrm{L}$ and was stored at $4{ }^{\circ} \mathrm{C}$ till further use [14].

\subsection{Anaerobic codigestion of food waste and septic tank sludge}

The different combinations of the feedstock, kitchen cooked food waste and anaerobic sludge, were used. The batch test comprised of digesters of $100 \mathrm{ml}$ total volume capacity [16]. Initially, $65 \mathrm{~mL}$ inoculum, occupying twothird of the working volume, was filled in each of the digester and one-third volume was left for the biogas. Different blends of the FW and the anaerobic STS in proportions of $0: 100,25: 75,50: 50,60: 40,75: 25$, and 100:0 respectively, were added to the inoculum in respective weights required to maintain the organic loading rate of $2 \mathrm{~g} \mathrm{VS} / \mathrm{L}$. A blank comprising only of inoculums was also digested anaerobically. All the proportions were applied in triplicates to minimize the error. The digesters were purged with nitrogen gas, then tightly closed with rubber stoppers and sealed completely.

All the digesters were placed in an incubator with a temperature of $37 \pm 2{ }^{\circ} \mathrm{C}$ for a period of 90 days. All the digesters were carefully tilted upside down twice a day for uniform mixing. For an initial period of 15 days, the 
biogas produced was measured daily by volume displacement method. Later, the measurement was done on alternate days for the next 2 weeks. As the biogas production became asymptotic, the gas measurement was done once in 3 days, then once in 5 days and finally once in a week.

\subsection{Analytical study}

The initial preparation of samples for analysis of the characteristics of the feedstock and inoculum was carried out in accordance with the procedures described previously [2]. The TS, VS, moisture content, alkalinity, $\mathrm{pH}$ and COD test was performed as per Standard Methods [17]. Ultimate analysis ( $\mathrm{CHN}$ ) was determined using Elemental Analyzer (FLASH 2000; Thermo Scientific, USA) as per Zirkler et al. [18]. Heavy metals, moisture content and macronutrients were determined using the methods described previously [19]. Protein content was analysed according to Nelson and Sommers [20]. Bligh and Dyer method was followed for the determination of lipids and Anthrone method was followed for the carbohydrate's determination [21,22]. For examination of functional group present in the substrates, Fourier Transform Infra-Red (FTIR) spectroscopy (Neon 2000; Bruker, Germany) was performed.

\subsection{Multi criteria decision modelling}

Multi Criteria Decision Models (MCDM) mainly focus on choice, ranking and sorting. MCDM are normally applied for both indefinite set of scenarios and definite set of scenarios. Anaerobic digestion of different combinations of FW and STS present a definite set of scenarios having a definite set of output. Here for anaerobic codigestion, $\mathrm{pH}$, alkalinity, biogas yield, $\mathrm{C} / \mathrm{N}$ and VS reduction may be considered as definite set of output [13]. For definite set of scenarios, there are many MCDM techniques such as ELECTRE (elimination et choix traduisant la realit'e), PROMETHEE (preference ranking organization method of enrichment evaluation), TOPSIS (technique for order preference by similarity to ideal solution), and VIKOR (VlseKriterijuska Optimizacija I Komoromisno Resenje) [13]. For present study, VIKOR and TOPSIS techniques have been selected as these two techniques have been explored for anaerobic digestion in solid state condition [13].

The indexes used in the analysis are VIKOR index for VIKOR analysis and closeness index (CI) for TOPSIS analysis and these are mathematical expressions. Both the VIKOR index for VIKOR analysis and closeness index for TOPSIS analysis provide ranks to the input alternatives. For VIKOR analysis, smallest VIKOR index is best solution employing VIKOR method. The VIKOR index, in general, proposes a solution which is close to the ideal point. TOPSIS defines an index called closeness index $(\mathrm{Cl})$ to the ideal solution. An alternative with maximum $\mathrm{Cl}$ value is preferred to be chosen from TOPSIS analysis.

The following sequential steps are followed in VIKOR method:

Step 1 Create a decision matrix of alternative selected for experiment and output.

$D_{m n}=\left[\begin{array}{lll}X_{11} & X_{12} & X_{1 m} \\ X_{21} & X_{22} & X_{2 m} \\ X_{n 1} & \cdots & \cdots\end{array}\right]$

Step 2 Create a normalized matrix using

$p_{i j=\frac{x_{i j}}{\sum_{i=n}^{i=1} x_{i j}}}$

Step 3 After creating normalized matrix, find entropy of each alternative

$E_{j}=-K \sum_{i=1}^{m} p_{i j} \ln \left(p_{i j}\right)$

where $\mathrm{K}=1 / \mathrm{ln}(\mathrm{m})$

Step 4 Calculate dispersion value of each alternative

$\pi_{j}=1-E_{j}$

Step 5 Find weight of each alternative

$\omega_{i j}=\frac{\pi_{j}}{\sum_{j=1}^{n} \pi_{j}}$

Step 6 Determine utility measure $\left(\alpha_{i}\right)$ and regret measure $\left(\beta_{\mathrm{i}}\right)$ using weights of each alternative from decision matrix; obtain maximum $\left(X_{i j m a x}\right)$ and minimum $\left(X_{i j m i n}\right)$ value for each output.

$\alpha_{i}=\sum_{j=1}^{n} \omega_{j} \frac{\left[X_{i j m a x}-X_{i j}\right]}{\left[X_{i j m a x}-X_{i j m i n}\right]}$

(If $\mathrm{j}$ is benefit criterion, for $\mathrm{j}=1,2 \ldots \mathrm{m}$ )

$\alpha_{i}=\sum_{j=1}^{n} \omega_{j} \frac{\left[X_{i j}-X_{i j m i n}\right]}{\left[X_{i j m a x}-X_{i j m i n}\right]}$

(If $\mathrm{j}$ is cost criterion, for $\mathrm{j}=1,2 \ldots \mathrm{m}$ )

$\beta_{\mathrm{i}}=\max$ of $\left\{\omega_{\mathrm{j}}\left[\frac{\mathrm{X}_{\mathrm{ij}}-\mathrm{X}_{\mathrm{ijmin}}}{\mathrm{X}_{\mathrm{ijmax}}-\mathrm{X}_{\mathrm{ijmin}}}\right]\right\}$

for $j=1,2, \ldots m$

Step 7 . Finally calculate VIKOR index, $\Omega_{\mathrm{i}}$

$\Omega_{\mathrm{i}}=\varepsilon \frac{\left(\alpha_{\mathrm{i}}-\alpha_{\mathrm{i}}^{-}\right)}{\left(\alpha_{\mathrm{i}}^{+}-\alpha_{\mathrm{i}}^{-}\right)}+(1-\varepsilon) \frac{\left(\beta_{\mathrm{i}}-\beta_{\mathrm{i}}^{-}\right)}{\left(\beta_{\mathrm{i}}^{+}-\beta_{\mathrm{i}}^{-}\right)}$ 
where $\alpha_{i}^{+}$and $\beta_{i}^{+}=\max$ of $\alpha_{i}$ and $\beta_{i}(i=1,2, \ldots m)$ and $\alpha_{i}^{-}$and $\beta_{i}^{-}=\min$ of $\alpha_{i}$ and $\beta_{i}(i=1,2, \ldots m)$.

$\varepsilon$ is introduced as weight for the maximum value of utility and $(1-\varepsilon)$ is the weight of the individual regret and normally value of $\varepsilon$ is taken as 0.5 .

The TOPSIS (technique for order preference by similarity to ideal solution) has wide applicability and is used for tackling ranking problems due to its simplicity. The steps involved in TOPSIS are as follows:

Step 1: Create a Decision Matrix. If the number of alternatives is $M$ and the number of performances defining criterion are $\mathrm{N}$ then the decision matrix having an order of $M \times N$ is represented as:

$D_{M N}=\left[\begin{array}{lll}X_{11} & X_{12} & X_{1 M} \\ X_{21} & X_{22} & X_{2 M} \\ X_{N 1} & \cdots & \cdots\end{array}\right]$

where an element $\mathrm{a}_{\mathrm{ij}}$ of the decision matrix $\mathrm{D}_{\mathrm{MN}}$ represents the actual value of the ith alternative in term of jth PDA

Step 2: Create Normalized Matrix. The normalized matrix $\mathrm{R}=[]$, and the normalized value calculated as:

$r_{i j}=\frac{a_{i j}}{\left[\int_{i=1}^{M}\left(a_{i j}^{2}\right)\right]}$

Step 3: Find out positive and negative ideal solution. The positive ideal solution (PIS) and the negative ideal solution (NIS) are determined based on the weighted normalized ratings as:

$A^{+}=\left(r_{1}^{+}, r_{2}^{+}, r_{N}^{+}\right)$

and

$A^{-}=\left(r_{1}^{-}, r_{2}^{-}, r_{N}^{-}\right)$

where

$r_{j}^{+}=\left(\frac{\left(\max _{i} r_{i j}\right) \text { if } j \text { is benefit criterion }}{\left(\min _{i} r_{i j}\right) \text { if } j \text { is cost criterion }}\right)$ and

$r_{j}^{-}=\left(\frac{\left(\min _{i} r_{i j}\right) \text { ifjisbenefitcriterion }}{\left(\max _{i} r_{i j}\right) \text { ifjiscostcriterion }}\right)$

where $\mathrm{j}=1,2,3 \ldots \mathrm{N}$

Step 4: Calculate the Euclidian distances between each of the alternatives and the positive ideal solution and the negative ideal solution

$D_{i}^{+}=\sqrt{\int_{j=1}^{N}\left(r_{i}^{+}-r_{i j}\right)^{2}}$ and

$D_{i}^{-}=\sqrt{\int_{j=1}^{N}\left(r_{i}^{-}-r_{i j}\right)^{2}}$

where $i=1,2 \ldots M$

Step 5: Finally find out closeness index $(\mathrm{Cl})$ and then give the ranking according to best outcomes. All the alternatives are then arranged in descending order according to the value of their closeness index. The alternative at the top of the list is the most preferred one. The closeness index $(\mathrm{Cl})$ of the alternatives is calculated as:

$C l_{i}=\frac{D_{i}^{-}}{D_{i}^{-}+D_{i}^{+}}$

where $i=1,2, \ldots M$

\subsection{Principal component analysis}

Principal component analysis (PCA) is an exploratory and iterative method which aims at reducing the original variables into reduced number of orthogonal (non-correlated) and synthesized variables or factors. These factors are often called Eigen vectors. In PCA algorithm, the axis is chosen such that when the samples are projected on it, the loss of variance of the projection is minimum for the cloud of points. PCA was applied to the batch experiments data to see the linear correlation between the explanatory output variables such as $\mathrm{pH}, \mathrm{COD}$, biogas, alkalinity, $\mathrm{C} / \mathrm{N}$ and VS reduction. The statistical analysis was performed on Minitab software 2015 version.

\subsection{Analysis of data}

One-way analysis of variance (ANOVA) with a threshold $p$ value 0.05 , were applied to test statistical significance of the data. Microsoft Excel 2016 with solver function was used for statistical test. This was performed to see standard deviation and mean for each set, as all the experiments were run in triplicate.

\section{Results and discussion}

\subsection{Characterization of feedstock and inoculum}

The proximate analysis, physical and chemical characteristics, heavy metals, nutritional content analysis and ultimate analysis of the feedstock are given in Table 1.

The highest percentage of volatile solids (around 90\%) is present in the food waste, which defines the maximum organic fraction of solids, making it easily amenable for 
Table 1 Characteristics of feed stocks used for biogas potential study

\begin{tabular}{|c|c|c|c|c|}
\hline Parameters & Units & Food waste & Septic tank sludge & Inoculum \\
\hline Moisture content (MC) & $\%$ & $85.27 \pm 1.62$ & $83.70 \pm 1.81$ & $74.07 \pm 0.50$ \\
\hline Total solids (TS) & $\%$ & $14.73 \pm 1.53$ & $16.30 \pm 1.80$ & $25.93 \pm 0.44$ \\
\hline Total volatile solids (VS) & $\%$ of TS & $89.83 \pm 6.90$ & $38.69 \pm 2.69$ & $43.38 \pm 18.00$ \\
\hline Fixed solids (FS) & $\%$ & $10.17 \pm 6.00$ & $61.41 \pm 2.70$ & $56.62 \pm 18.19$ \\
\hline $\mathrm{pH}$ & - & $5.4 \pm 0.5$ & $6.9 \pm 0.4$ & $6.7 \pm 0.7$ \\
\hline Chemical oxygen demand (COD) & $\mathrm{mg} / \mathrm{l}$ & 344,890 & 8700 & 3400 \\
\hline Alkalinity & $\mathrm{mg} / \mathrm{l}$ as $\mathrm{CaCO}_{3}$ & 40 & 20 & 10 \\
\hline Proteins & $\%$ & 18.79 & AND & AND \\
\hline Lipids & $\%$ & 16.98 & AND & AND \\
\hline Fibres & $\%$ & 8.88 & AND & AND \\
\hline Carbohydrates & $\%$ & 47.60 & AND & AND \\
\hline Iron (Fe) & $\mathrm{mg} / \mathrm{l}$ & 12.80 & 120.00 & 19.80 \\
\hline Nickel (Ni) & $\mathrm{mg} / \mathrm{l}$ & $\mathrm{BDL}$ & 12.80 & 16.10 \\
\hline Manganese (Mn) & $\mathrm{mg} / \mathrm{l}$ & $\mathrm{BDL}$ & 87.80 & 5.90 \\
\hline Zinc (Zn) & $\mathrm{mg} / \mathrm{l}$ & 0.90 & 18.50 & 12.60 \\
\hline Calcium (Ca) & $\mathrm{mg} / \mathrm{l}$ & 352.50 & 3743.60 & 1300.90 \\
\hline Total carbon & $\%$ & 41.33 & 28.5 & 23.13 \\
\hline Total hydrogen & $\%$ & 6.96 & 3.96 & 3.21 \\
\hline Total nitrogen & $\%$ & 4 & 3.23 & 1.99 \\
\hline Total oxygen ${ }^{a}$ & $\%$ & 47.71 & 64.31 & 72.45 \\
\hline $\mathrm{C} / \mathrm{N}$ ratio & & 10.33 & 8.82 & 11.61 \\
\hline
\end{tabular}

${ }^{a}$ Oxygen value was calculated by subtracting $\mathrm{C}, \mathrm{N}$ and $\mathrm{H}$ values from $100 \%$ [2]

$A N D$ analysis not done, $B D L$ below detection limit $<0.00 \mathrm{mg} / \mathrm{l}$ biogas production thereby contributing to resource recovery. A significant segment of food waste is moisture laden $(85 \%)$ accounting for its easy biodegradability. Anaerobic sludge obtained from septic tank has good moisture content as well as solids content, but it has fewer volatile solids content making biogas production difficult. FW has $\mathrm{pH}$ range of $5.4 \pm 0.5$ due to the natural acidogenesis of the leftover meals, which start degrading if unattended for a longer period of time [23]. The prevailing anaerobic condition results in the $\mathrm{pH}$ values of $6.9 \pm 0.4$ for the STS. Variety of organic content in the form of carbohydrates, proteins, lipids and fibres in FW may be the reason for a considerably significant value of $344,890 \mathrm{mg} / \mathrm{l}$ of COD [24]. The high value of COD obtained for sludge may be attributed to the oxidation and fermentation of the food consumed by the human beings, inside their digestive tract. The consumed food comprises of various spices and different methods of preparation contributing to complex organic matter.

The availability of certain elements, as trace metals, often called as micronutrients, below a certain threshold value helps in biogas production. Micronutrients such as iron, zinc, manganese, nickel and calcium affect the metabolism of biogas production. Appropriate determination of trace elements in the substrates is essential as it provides an idea about the supplements required for the efficient treatment and management of the feedstock
[25]. Recommended concentration for iron in anaerobic digestion is $1-10 \mathrm{mg} / \mathrm{l}$ and $0.28-50.4 \mathrm{mg} / \mathrm{l}[26,27]$. Iron enhances the redox property and acts as electron acceptor, thus maintaining the synergy between microbes and enhancing the biomethanation of substrate. STS has excessive concentration of iron which may results in disturbing the synergy and ultimately leads to microbial inhibition. Nickel is responsible for synthesis of coenzymes [25]. Bozym et al. [28] reported the threshold limit for nickel to be $10 \mathrm{mg} / \mathrm{l}$. For the process stability, minimum recommended value of nickel is $0.005 \mathrm{mg} / \mathrm{l}$ [26]. The presence of manganese in a concentration of about $0.005-50 \mathrm{mg} / \mathrm{l}$ is essential for the occurrence of redox reaction. It activates the enzymes of bacteria and cofactor of various enzymes [25]. Davis and Greger [29] reported excretion of entire manganese absorbed in the body through food in the faeces. As STS is having excessive concentration of nickel and manganese beyond the threshold value, toxicity may be introduced in the digester affecting the biogas production and process stability. To overcome the adverse effects caused by the presence of other complex and toxic compounds, zinc is required. It also acts as metallic enzyme activator and stimulates cell growth [25]. The maximum recommended limit of zinc for anaerobic digestion is $1 \mathrm{mg} / \mathrm{l}$ [28]. The ability to resist a major change in $\mathrm{pH}$ is governed by the element calcium; as it provides buffering 
capacity to the digester [28]. It also enhances the membrane permeability of the microbes [25]. The threshold limit of calcium is $2800 \mathrm{mg} / \mathrm{l}$ [27]. Protein presence in the form of different types of pulses and lentils gave around $4 \%$ nitrogen content whereas carbohydrates were $47.6 \%$. Hence co-digestion was essential to obtain optimum C/N ratio of $25-30$.

\subsection{Effect of anaerobic co-digestion on biogas production}

The batch test was performed to check the feasibility of the substrates for biomethanation potential and the degree of amenability of the individual substrates as well as the substrates in combination with the other substrates for co-digestion. It is essential to determine the ultimate biogas potential for different combinations of solid substrates to arrive at the optimal combination. In fact, this is a key parameter for assessing design, economics and managing issues for the full-scale implementation of anaerobic digestion processes utilising different substrates. Due to the differences in equipment, operation conditions, experimental protocols, and calculation methods, BMP assays of substrates conducted by different researchers are usually not comparable [16]. The residue in the digesters comprising of only food waste was even less than $1 \%$ of the entire feed volume.

Biogas measurements were performed following the principle of volume displacement in water. Total biogas yield was summed up to observe the cumulative gas yield which was converted in terms of the applied loading rate. The cumulative biogas yield of each feedstock is presented through the graph in Fig. 1.
The biogas potential for FW agreed with the other reported studies for biogas production from FW. Moreover, reported biogas yields from FW may vary due to the heterogeneous nature of the FW and variation in nutrient content depending on the type, origin and processing of FW. Furthermore, as the content of the FW is reduced and the STS content is increased, the yield of biogas is decreased. This may be attributed to the fact that as the sludge was stabilized, the microbes didn't find sufficient nutrition and food for their growth. It is also apparent that the reaction rate for STS is higher than for FW, due to complex nature of organic matter in FW.

\subsection{Reactor characteristics}

Determination of COD and $\mathrm{pH}$ involved uniform sampling throughout the digestate (supernatant and residue) for all the blends of feedstock and inoculum, whereas for the determination of solids, the residue was filtered and allowed to dry. The obtained results yielded a significant drop in the values of various parameters evaluated after the digestion in comparison to the respective parameter values before digestion. The results of the anaerobic digestion and co-digestion are provided in Table 2 and Fig. 2 respectively.

Maximum biogas potential is showed by the food waste. $\mathrm{pH}$ of the digestate is always in alkaline range (above 7) for all the blends. It is evident from increase in the alkalinity of the samples that the codigestion of food waste and septic tank sludge proves to be synergistic [30]. An enormous reduction of around $98 \%$ in the value of $C O D$ has been obtained, but a significant value of $6800 \mathrm{mg} / \mathrm{l}$ persists. Reduced inorganic species such as ferrous iron and manganese may not be oxidized completely. Up to
Fig. 1 Experimental Biogas production potential of different blends used in batch test

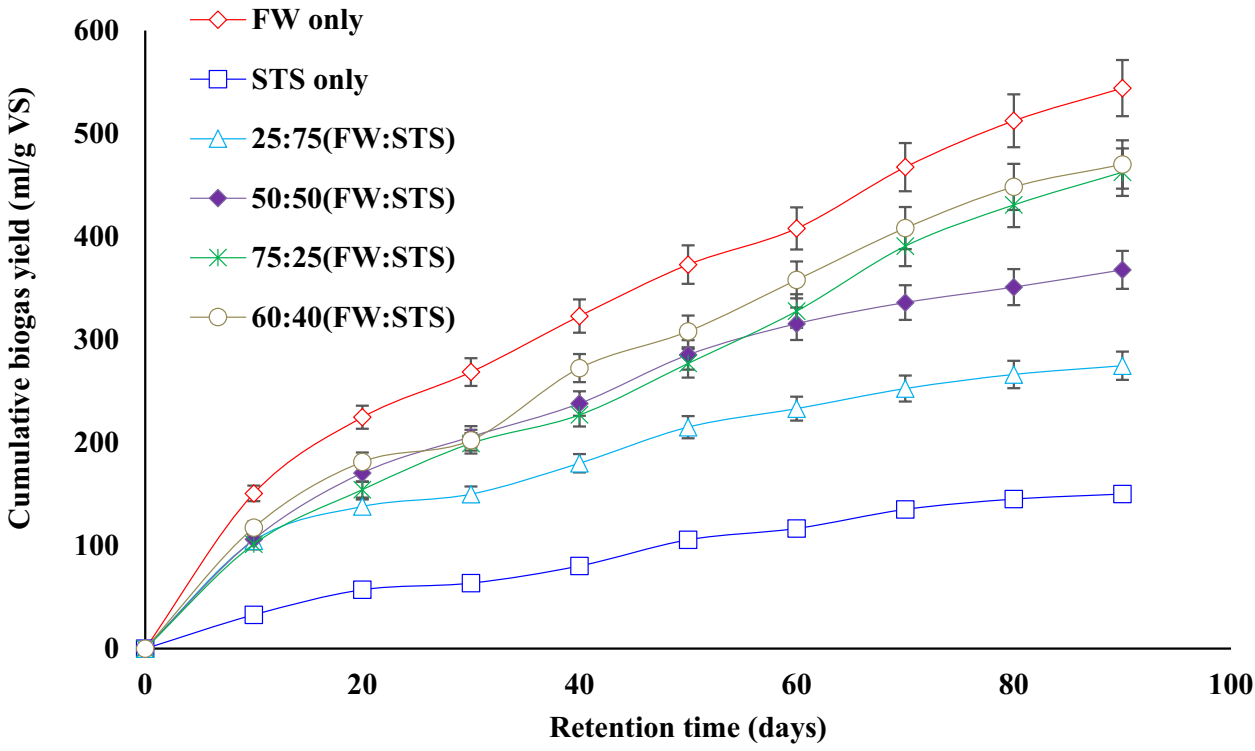


Table 2 Characteristics of contents of different blends of reactor after anaerobic digestion

Fig. 2 A contour plot of output variables showing correlation among a biogas, VS reduction and COD removal and $\mathbf{b}$ biogas. $\mathrm{C} / \mathrm{N}$ ratio and alkalinity

\begin{tabular}{|c|c|c|c|c|c|c|c|c|}
\hline S. No. & Samples & $\mathrm{PH}$ & $\begin{array}{l}\text { VS reduc- } \\
\text { tion (\% of } \\
\text { TS) }\end{array}$ & $\begin{array}{l}\text { VS reduc- } \\
\text { tion as } \\
\mathrm{g} / \mathrm{L}\end{array}$ & $\mathrm{COD}(\mathrm{mg} / \mathrm{L})$ & $\begin{array}{l}\text { Alkalinity } \\
\text { (mg/L as } \\
\mathrm{CaCO}_{3}\end{array}$ & $\begin{array}{l}\text { Biogas } \\
\text { yield }(\mathrm{ml} / \mathrm{g} \\
\text { VS) }\end{array}$ & $\mathrm{C} / \mathrm{N}$ \\
\hline 1 & Blank & 7.5 & 17.75 & 0.335 & 6160.0 & 150.0 & 28.23 & 22.0 \\
\hline 2 & STS only & 7.3 & 32.0 & 0.64 & 4060.0 & 150.0 & 150.03 & 15.0 \\
\hline 3 & FW only & 7.8 & 43.0 & 0.86 & 6800.0 & 250.0 & 544.10 & 33.0 \\
\hline 4 & 25:75 (FW: STS) & 7.3 & 35.0 & 0.70 & 5700.0 & 300.0 & 274.54 & 21.0 \\
\hline 5 & $\begin{array}{l}\text { 50:50 } \\
\text { (FW: STS) }\end{array}$ & 7.6 & 36.0 & 0.72 & 6840.0 & 200.0 & 367.63 & 24.0 \\
\hline 6 & $\begin{array}{l}60: 40 \\
\text { (FW: STS) }\end{array}$ & 7.1 & 38.0 & 0.76 & 6896.0 & 300.0 & 462.49 & 27.0 \\
\hline 7 & 75:25 (FW: STS) & 7.7 & 41.0 & 0.82 & 5080.0 & 155.0 & 470.00 & 30.0 \\
\hline
\end{tabular}
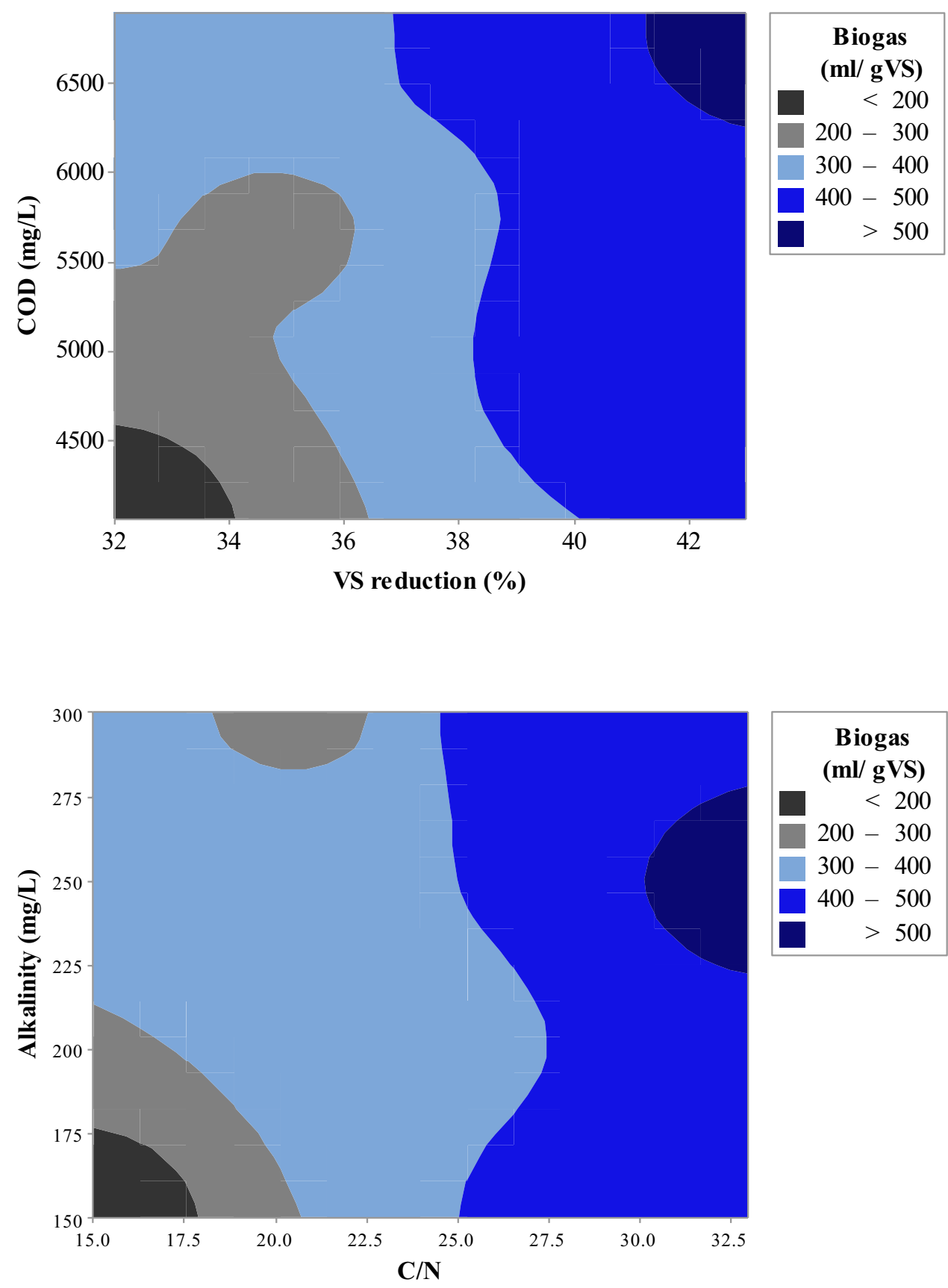


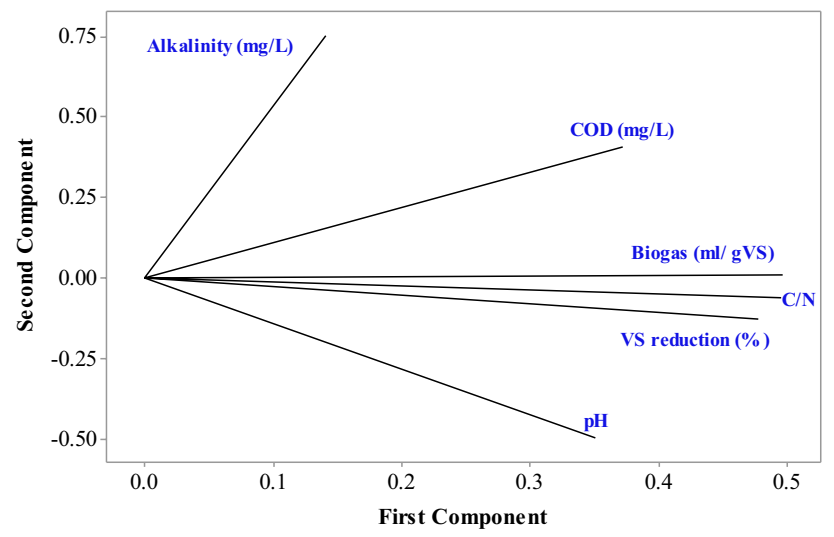

Fig. 3 Loading plot of output variables

$43 \%$ volatile solids reduction has been obtained, which is acceptable but on the lower side as reported in literature (35-70\%) [31]. This lower VS may be due to uneven $\mathrm{pH}$ and VFA accumulation resulting in inaccessibility of a part of the organic material [13]. A fraction of the substrate may have been utilized to synthesize bacterial mass, typically $5-10 \%$ of the organic material degraded. However, VS reduction was positively correlated $\left(R^{2}=0.9115\right)$ with biogas yield. This is shown in Fig. 3. After a certain time, there could be limitation of other nutrient factors.

\subsection{Fourier transform infra-red analysis}

Fourier Transform Infra-Red (FTIR) Spectroscopy was used as a tool for identification of functional groups. FTIR was performed to identify the types of functional groups present in the food waste, septic tank sludge and the inoculum before and after digestion. These functional groups were able to explain the reason behind the value of COD that still remained in the substrates after the anaerobic co-digestion.

The ordinate defines the percentage of transmittance against the wave number provided by the abscissa. The spectrum revealed the chemical composition of the substrates as a subset of qualitative analysis. The graph of FTIR data, which is described below is a part of supplementary material. The peak observed near the region of $2850-2925 \mathrm{~cm}^{-1}$ may be attributed to the presence of carbohydrates and protein. The $\mathrm{N}-\mathrm{H}$ stretch of amines and the $\mathrm{C}-\mathrm{H}$ stretch of alkanes is centred to the region of $3400-3500 \mathrm{~cm}^{-1}$ [2]. This shows that these complex compounds are remaining after the digestion and contributing to the COD.

\subsection{Multi criteria decision modelling}

After the completion of batch anaerobic co-digestion, lots of post treatment analysis performed and data are generated. In this regards, $\mathrm{pH}$, alkalinity, VS reduction, COD and $\mathrm{C} / \mathrm{N}$ were calculated. Possible alternatives (FW: STS blending combination for digestion) were arranged against data obtained from post treatment analysis in matrix form (Table 3). After the creating decision matrix, normalized matrices were created using Eqs. 2 and 11 for VIKOR and TOPSIS method respectively (Tables 4 and 5). For VIKOR method, value of entropy, dispersion and weight of each alternative were calculated. The alternative which obtained highest rank by VIKOR method (Table 6) shows closeness to the ideal solution while highest rank secured by alternative through TOPSIS method (Table 7) shows the
Table 3 Decision matrix for possible feedstock alternatives selected for multi criteria analysis

\begin{tabular}{lllllll}
\hline Alternatives & VS reduction & COD & PH & Biogas & Alkalinity & C/N \\
\hline STS & 32 & 4060 & 7 & 150 & 150 & 15 \\
FW & 43 & 6800 & 8 & 544 & 250 & 33 \\
25:75 (FW: STS) & 35 & 5700 & 7 & 275 & 300 & 21 \\
50:50 (FW: STS) & 36 & 6840 & 8 & 368 & 200 & 24 \\
60:40 (FW: STS) & 38 & 6896 & 7 & 462 & 300 & 27 \\
75:25 (FW: STS) & 41 & 5080 & 8 & 470 & 155 & 30 \\
\hline
\end{tabular}

Table 4 Normalized matrix for VIKOR analysis

\begin{tabular}{lllllll}
\hline Alternatives & VS reduction & COD & PH & Biogas & Alkalinity & C/N \\
\hline STS & 0.1570 & 0.1623 & 0.1750 & 0.1571 & 0.1340 & 0.1881 \\
FW & 0.1928 & 0.1461 & 0.1500 & 0.1714 & 0.1443 & 0.1536 \\
25:75 (FW: STS) & 0.1659 & 0.1542 & 0.1750 & 0.1286 & 0.2062 & 0.1571 \\
50:50 (FW: STS) & 0.1704 & 0.1867 & 0.1500 & 0.1857 & 0.1546 & 0.1558 \\
60:40 (FW: STS) & 0.1435 & 0.1989 & 0.2000 & 0.1571 & 0.1753 & 0.1699 \\
75:25 (FW: STS) & 0.1704 & 0.1518 & 0.1500 & 0.2000 & 0.1856 & 0.1755 \\
\hline
\end{tabular}


Table 5 Normalized matrix for TOPSIS analysis

\begin{tabular}{llllll}
\hline Alternatives & VS reduction & COD & PH & Biogas & Alkalinity \\
\hline STS & 0.3829 & 0.0008 & 0.0259 & 0.0004 & 0.0081 \\
FW & 0.4704 & 0.0007 & 0.0222 & 0.0003 & 0.0087 \\
25:75 (FW: STS) & 0.4048 & 0.0007 & 0.0259 & 0.0003 & 0.0125 \\
50:50 (FW: STS) & 0.4157 & 0.0009 & 0.0222 & 0.0003 & 0.0094 \\
60:40 (FW: STS) & 0.3501 & 0.0010 & 0.0296 & 0.0003 & 0.0106 \\
75:25 (FW: STS) & 0.4157 & 0.0007 & 0.0222 & 0.0003 & 0.0112 \\
\hline
\end{tabular}

Table 6 Utility measure, regret measure and VIKOR Index for ranking of alternatives

\begin{tabular}{lllll}
\hline Alternatives & $\begin{array}{l}\text { Utility meas- } \\
\text { ure }\end{array}$ & $\begin{array}{l}\text { Regret meas- } \\
\text { ure }\end{array}$ & VIKOR index & Rank \\
\hline STS & 0.235 & 0.041 & 0.182 & 2 \\
FW & 0.099 & 0.090 & 0.135 & 1 \\
$25: 75$ (FW: & 0.325 & 0.074 & 0.377 & 3 \\
$\begin{array}{l}\text { STS) } \\
\text { 50:50 (FW: }\end{array}$ & 0.397 & 0.103 & 0.548 & 4 \\
$\begin{array}{l}\text { STS) } \\
\text { 60:40 (FW: } \\
\text { STS) }\end{array}$ & 0.427 & 0.214 & 0.906 & 5 \\
$\begin{array}{c}75: 25 \text { (FW: } \\
\text { STS) }\end{array}$ & 0.503 & 0.213 & 0.996 & 6 \\
\hline
\end{tabular}

Table 7 The Euclidian distances between the positive and negative ideal solutions and the rank of alternatives for TOPSIS method

\begin{tabular}{llllll}
\hline Alternatives & $\mathrm{Di}+$ & $\mathrm{Di}-$ & $\mathrm{Di}++\mathrm{Di}-$ & $\mathrm{Cl}$ & Rank \\
\hline STS & 4.737 & 0.797 & 5.534 & 0.144 & 2 \\
FW & 4.176 & 0.643 & 4.819 & 0.133 & 4 \\
25:75 (FW: STS) & 4.472 & 0.670 & 5.142 & 0.130 & 5 \\
50:50 (FW: STS) & 4.416 & 0.650 & 5.067 & 0.128 & 6 \\
60:40 (FW: STS) & 4.261 & 0.660 & 4.922 & 0.134 & 3 \\
75:25 (FW: STS) & 4.355 & 0.694 & 5.050 & 0.147 & 1 \\
\hline
\end{tabular}

best one in terms of ranking index. Though the food waste yielded maximum biogas as compared to other blended feedstock co-digestion, but the mixing ratio of food waste and septic tank sludge got first rank as per MCDM (TOP$\mathrm{SIS}$ ). This suggests that if a bioreactor is to be considered for multiple responses such as biogas yield, COD reduction, optimal $\mathrm{pH}$ and alkalinity, optimal $\mathrm{C} / \mathrm{N}$ ratio, VS reduction-co-digestion of food waste with septic tank sludge should be preferred. Moreover, the rank provided to the alternatives by TOPSIS may not be close to the ideal solution and experimental results validate this statement. Similar results were obtained by Paritosh et al. [13] while applying TOPSIS and VIKOR for prioritizing the temperature and solid concentration for solid state anaerobic digestion of pearl millet straw. It was reported that ranking provided by VIKOR analysis showed agreement with the experimental investigation while TOPSIS provided ranking based on closeness index. In another study, Gandhi et al. [32] employed VIKOR for thermally pretreated food waste for biogas production. The alternative in which temperature and time was $100{ }^{\circ} \mathrm{C}$ and $10 \mathrm{~min}$, showed $41 \%$ increased biogas yield as compared to control. MCDM analysis showed that VIKOR provided similar ranking as per experimental results. These investigations including present study showed that for anaerobic digestion, VIKOR may provide best alternative.

\subsection{Principal component analysis}

Principal component analysis was performed to see the linear correlation between the explanatory variables. The loading plot provided in Fig. 3, shows the linear correlation between the outputs. Each line represents a single output and angle between two line shows the relation between them. The angle tending to zero $\left(\operatorname{Cosine} 0^{\circ}=1\right)$, represents a strong correlation and angle of $180^{\circ}\left(\right.$ Cosine $\left.180^{\circ}=-1\right)$ shows inverse relationship. If the angle between two lines is $90^{\circ}\left(\right.$ Cosine $\left.90^{\circ}=0\right)$, there is no linear relation between the outputs. As per PCA analysis, biogas yield, VS reduction and $\mathrm{C} / \mathrm{N}$ ratio are strongly linearly correlated which shows that biogas production strongly depends on $\mathrm{C} / \mathrm{N}$ ratio and VS reduction in co-digestion process. More the organic content in the substrate, more readily the biogas formation occurs and so greater will be the volatilization of solids. The $\mathrm{pH}$ and alkalinity are not strongly correlated with biogas production as per PCA analyses of anaerobic co-digestion experiment. Since, co-digestion establishes synergy and symbiotic relationship in the microbial population involved in $A D$, providing conditions for optimum gas production without additional requirement of buffers. The COD and biogas production show not that strong correlation, as complex compounds of aromatic and heterogeneous nature create barriers in the biogas formation, so they do not get oxidized to appreciable extent.

\section{Conclusion}

Multi Criteria Decision Modelling may be helpful for selecting the best input criteria depending upon multiple output. In this study, experimental results of anaerobic co digestion of FW and fresh STS has been validated by VIKOR method. Anaerobic co-digestion with STS resulted in low biogas production due to excessive concentration of zinc and manganese. FTIR details out the complex compounds contributing to high COD values. Apart from TOPSIS and VIKOR, there are other MCDM which may be employed 
for further investigation. In addition to this, application of MCDM technique is required to be explored in the field of anaerobic digestion for the decision making and for upscaling the process for energy application.

\section{Supplementary materials}

Supplementary file has been attached which comprise of FTIR spectra before and after anaerobic co-digestion of food waste, septic tank sludge and inoculum respectively. Details of different functional groups present is also mentioned.

Acknowledgements Nupur Kesharwani thanks National Institute of Technology Raipur for the financial support and facilities provided to carry out the research.

\section{Compliance with ethical standards}

Conflict of interest The authors declare no conflict of interest.

\section{References}

1. Venkateshkumar R, Shanmugam S, Veerappan AR (2019) Experimental investigation on the effect of anaerobic co-digestion of cotton seed hull with cow dung. Biomass Convers Bioref 1-8. https://doi.org/10.1007/s13399-019-00523-0

2. Paritosh K, Mathur S, Pareek N, Vivekanand V (2018) Feasibility study of waste (d) potential: co-digestion of organic wastes, synergistic effect and kinetics of biogas production. Int J Env Sci Technol 15:1009-1018

3. Abudi ZN, Hu Z, Sun N, Xiao B, Rajaa N, Liu C, Guo D (2016) Batch anaerobic co-digestion of OFMSW (organic fraction of municipal solid waste), TWAS (thickened waste activated sludge) and RS (rice straw): influence of TWAS and RS pretreatment and mixing ratio. Energy 107:131-140

4. Bhakov ZK, Korazbekova KU, Lakhanova KM (2014) The kinetics of biogas production from codigestion of cattle manure. Pak J Biol Sci 17:1023-1029

5. Paritosh K, Yadav M, Mathur S, Balan V, Liao W, Pareek N, Vivekanand V (2018) Organic fraction of municipal solid waste: overview of treatment methodologies to enhance anaerobic biodegradability. Front Energy Res 6:75

6. FAO (2012) Towards the future, we want: end hunger and make the transition to sustainable agricultural and food systems. Food and Agriculture Organization of the United Nations, Rome

7. Appels L, Lauwers J, Degreve J, Helsen L, Lievens B, Willems K, Impe JV, Dewil R (2011) Anaerobic digestion in global bioenergy production - potential and research challenges. Renew Sustain Energy Rev 15:4295-4301

8. Koch K, Drewes JE (2014) Alternative approach to estimate the hydrolysis rate constant of particulate material from batch data. Appl Energy 120:11-15

9. Koch K, Plabst M, Schmidt A, Helmreich B, Drewes JE (2016) Codigestion of food waste in a municipal wastewater treatment plant: comparison of batch tests and full-scale experiences. Waste Manag 47:28-33
10. Marañón E, Castrillón L, Quiroga G, Fernández-Nava Y, Gómez L, García MM (2012) Co-digestion of cattle manure with food waste and sludge to increase biogas production. Waste Manag 32:1821-1825

11. El-Mashad HM, Zhang R (2010) Biogas production from codigestion of dairy manure and food waste. Bioresour Technol 101:4021-4028

12. Harder R, Wielemaker R, Larsen TA, Zeeman G, Öberg G (2019) Recycling nutrients contained in human excreta to agriculture: pathways, processes, and products. Crit Rev Env Sci Technol 49:695-743

13. Paritosh K, Pareek N, Chawade A, Vivekanand V (2019) prioritization of solid concentration and temperature for solid state anaerobic digestion of pearl millet straw employing multicriteria assessment tool. Sci Rep 9:1-11

14. Yang Z, Wang W, Zhang S, Ma Z, Anwar N, Liu G, Zhang R (2017) Comparison of the methane production potential and biodegradability of kitchen waste from different sources under mesophilic and thermophilic conditions. Water Sci Technol 75:1607-1616

15. Garcia-Peña El, Parameswaran P, Kang DW, Canul-Chan M, Krajmalnik-Brown R (2011) Anaerobic digestion and co-digestion processes of vegetable and fruit residues: process and microbial ecology. Bioresour Technol 102:9447-9455

16. Angelidaki I, Alves $M$, Bolzonella $D$, Borzacconi L, Campos JL, Guwy AJ, Van Lier JB (2009) Defining the biomethane potential (BMP) of solid organic wastes and energy crops: a proposed protocol for batch assays. Water Sci Technol 59:927-934

17. APHA (1989) Standard methods for examination of water and waste water, 17th edn. American Public Health Association, Washington

18. Zirkler D, Peters A, Kaupenjohann M (2014) Elemental composition of biogas residues: variability and alteration during anaerobic digestio. Biomass Bioenerg 67:89-98

19. Black CA (1965) Methods of soil analysis. Part I. American Society of Agronomy, Madison, p 1572

20. Nelson DW, Sommers LE (1996) Total carbon, organic carbon, and organic matter, methods of soil analysis Part 3-chemical methods 961-1010.https://doi.org/10.2136/sssabookse r5.3.c34

21. Bligh EG, Dyer WJ (1959) A rapid method of total lipid extraction and purification. Can J Biochem Phys 37:911-917

22. Ludwig TG, Goldberg HJV (1956) The anthrone method for the determination of carbohydrates in foods and in oral rinsing. $J$ Dental Res 35:90-94

23. Bo Z, Pin-Jing H (2014) Performance assessment of twostage anaerobic digestion of kitchen wastes. Environ Technol 35:1277-1285

24. Tembhurkar AR, Mhaisalkar VA (2007) Studies on hydrolysis and acidogenesis of kitchen waste in two phase anaerobic digestion. JIPHE, India, p 2

25. Matheri AN, Belaid M, Seodigeng T, Ngila JC (2016) The role of trace elements on anaerobic co-digestion in biogas production. In: Proceedings of the World Congress on Engineering, London, UK

26. Weiland $P$ (2006) Biomass digestion in agriculture: a successful pathway for the energy production and waste treatment in Germany. Eng Life Sci 6:302-309

27. Speece RE, Parkin GF (1987) Nutrient requirements for anaerobic digestion. Biotechnological advances in processing municipal wastes for fuels and chemicals. Noyes Data Corporation, Park Ridge New Jersey

28. Bożym M, Florczak I, Zdanowska P, Wojdalski J, Klimkiewicz M (2015) An analysis of metal concentrations in food wastes for biogas production. Renew Energy 77:467-472 
29. Davis CD, Greger JL (1992) Longitudinal changes of manganese-dependent superoxide dismutase and other indexes of manganese and iron status in women. Am J Clin Nutr 55:747-752

30. Labatut RA, Angenent LT, Scott NR (2011) Biochemical methane potential and biodegradability of complex organic substrates. Bioresour Technol 102:2255-2264

31. Deepanraj B, Sivasubramanian V, Jayaraj S (2015) Kinetic study on the effect of temperature on biogas production using a lab scale batch reactor. Ecotox Environ Safe 121:100-104
32. Gandhi P, Paritosh K, Pareek N, Mathur S, Lizasoain J, Gronauer A, Bauer A, Vivekanand V (2018) Multicriteria decision model and thermal pretreatment of hotel food waste for robust output to biogas: case study from city of Jaipur. BioMed Res Int, India

Publisher's Note Springer Nature remains neutral with regard to jurisdictional claims in published maps and institutional affiliations. 